\title{
ANATEA, AN ANT-MIMICKING THERIDIID SPIDER FROM NEW CALEDONIA (ARANEAE: THERIDIIDAE)
}

\author{
By Jonathan Reiskind and Herbert W. Levi* \\ Museum of Comparative Zoology
}

The morphological and behavioral adaptations necessary for ant mimicry have arisen independently many, many times in spiders. Ant mimicry has originated at least four times in the Clubionidae, three times in the Salticidae, several times in the Theridiidae, Araneidae and Thomisidae, and also in the Gnaphosidae, Zodariidae and Eresidae. In addition the bizarre characteristics of these spiders have led spider specialists to group some of the stranger species into families - such as the Myrmecidae C. L. Koch i85i (mainly including antmimicking genera from the Micariinae of the Clubionidae) and the Aphantochilidae (a group of highly modified Thomisidae that mimic cephalotine ants). Walckenaer (I84I) included in the genus Myrmecia members of both the Clubionidae and the Salticidae, all good myrmecomorphs. This tendency to be biased by the outward modifications associated with ant mimicry resultea in the placing of Anatea formicaria Berland in the sub-family Micariinae (Clubionidae) when it was first described (Berland, 1927). Berland based his placement on general shape and male genitalia. The latter resembles the male genitalia of Micaria, but only in that both are quite simple and have a central sclerotized process.

Anatea formicaria Berland should be in the family Theridiidae. Closely related to Euryopis and possibly to Achaearanea, it lacks a colulus and has toothless cheliceral margins. The palpus, which lacks a radix, is simpler than in either Euryopis or Achaearanea but is definitely related. As in some Euryopis the abdomen is sclerotized with scuta and the chelicerae are very small with huge sickle-shaped fangs, possibly indicating that Anatea feeds on ants as do members of Euryopis and related Dipoena. The function of the sickle-shaped fang is not known although the unusual method used to catch ants by Euryopis flavomaculata C. L. Koch has been observed (D. Hirschberg in manuscr.). While it is unlikely that the mimicry would deceive an ant, the occurrence of the spider near the ants (a preypredator relationship) could account for strong selection pressure applied by predators of the spider.

*This investigation was supported in part by Public Health Service Research Grant AI-01944 from the National Institute of Allergy and Infectious Diseases.

Manuscript received by the editor April 3, 1967. 
There are four or five other known theridiid ant mimics: Cerocida strigosa Simon, Helvibis brasiliana (Keyserling) and H. chilensis (Keyserling), the male of Coleosoma floridanum Banks, and perhaps Hetschkia gracilis Keyserling. All except the Coleosoma create the impression of a petiole by a posterior elongation of the cephalothorax, most highly perfected in Cerocida where the "petiole" is rugose and sharply delimited from the rest of the carapace. Coleosoma floridanum has a highly constricted abdomen. But in Coleosoma only the males resemble ants, the females are characteristic sedentary theridiids hanging in a web.

Anatea formicaria, unlike any other theridiid, produces its "petiole" by an elongation of the pedicel. In addition the dorsum of the "petiole" is rugose and has a distinct "node" as is typical in most ants. The abdomen is globose and highly shiny - very much like an ant's gaster.

Anatea formicaria is an accurate mimic of the small myrmicine ant Chelaner croceiventre (Emery), $2.6 \mathrm{~mm}$ long, which has been collected at the same locality as the spider. The color pattern (dark brown anterior and light, yellow-brown posterior) of both is quite rare in ants and is also found in specimens of Xiphomyrma tenuierius Eme:y, $2.9 \mathrm{~mm}$ long, and a species of Lordomyrma, $4.8 \mathrm{~mm}$ long, two myrmicine ants found in the same area of rain forest (E. O. Wilson, pers. comm.). Myrmicine ants have large and well-developed stings and are therefore quite objectionable to most potential predators. Such a pattern may represent a mimetic complex with the ants being Müllerian mimics and the spider a Batesian mimic of one or more ants.

The genus Anatea will presumably key out to Euryopis in the key to theridiid genera (Levi and Levi I962) but differs from Euryopis in having a simpler palpus (Figs. 3-6) and from all theridiid genera in the extraordinary development of the pedicel, and the strong first legs. Berland indicates that the female resembles the male.

\section{Anatea formicaria Berland 1927}

Figs. I-6

Description: Male. Carapace, sternum brown and sclerotized, legs lighter brown. Dorsum of abdomen light brown with four darker areas and a polished, shiny surface. Eyes subequal in size. Anterior median eyes about one-half diameter apart, a little more than one diameter from laterals. Posterior median eyes their radius apart, one and one-quarter diameters from laterals. The pedicel is unusually long with a joint at each end. The chelicerae are weak 
with fang longer than basal segment. Abdomen has a dorsal shield wrapped around it, partly covering venter (Figs. I, 2). Tracheal spiracle far anterior (Fig. 2). Legs almost equal in length; first tarsi and metatarsi thicker than tibiae. Tarsal comb on fourth legs reduced or absent. Total length $2.5 \mathrm{~mm}$. Carapace $0.84 \mathrm{~mm}$; pedicel $0.62 \mathrm{~mm}$; abdomen $1.04 \mathrm{~mm}$ long. First femur, $0.63 \mathrm{~mm}$; patella and tibia, $0.67 \mathrm{~mm}$; metatarsus, $0.36 \mathrm{~mm}$; tarsus, $0.28 \mathrm{~mm}$. Second patella and tibia, $0.63 \mathrm{~mm}$; third patella and tibia, $0.60 \mathrm{~mm}$. Fourth femur, $0.63 \mathrm{~mm}$; patella and tibia, $0.75 \mathrm{~mm}$; metatarsus, $0.42 \mathrm{~mm}$; tarsus, $0.34 \mathrm{~mm}$.

The palpus is very simple (Fig. 3-6). Using the nomenclature of palpal sclerites used in the theridiid revisions, the median apophysis

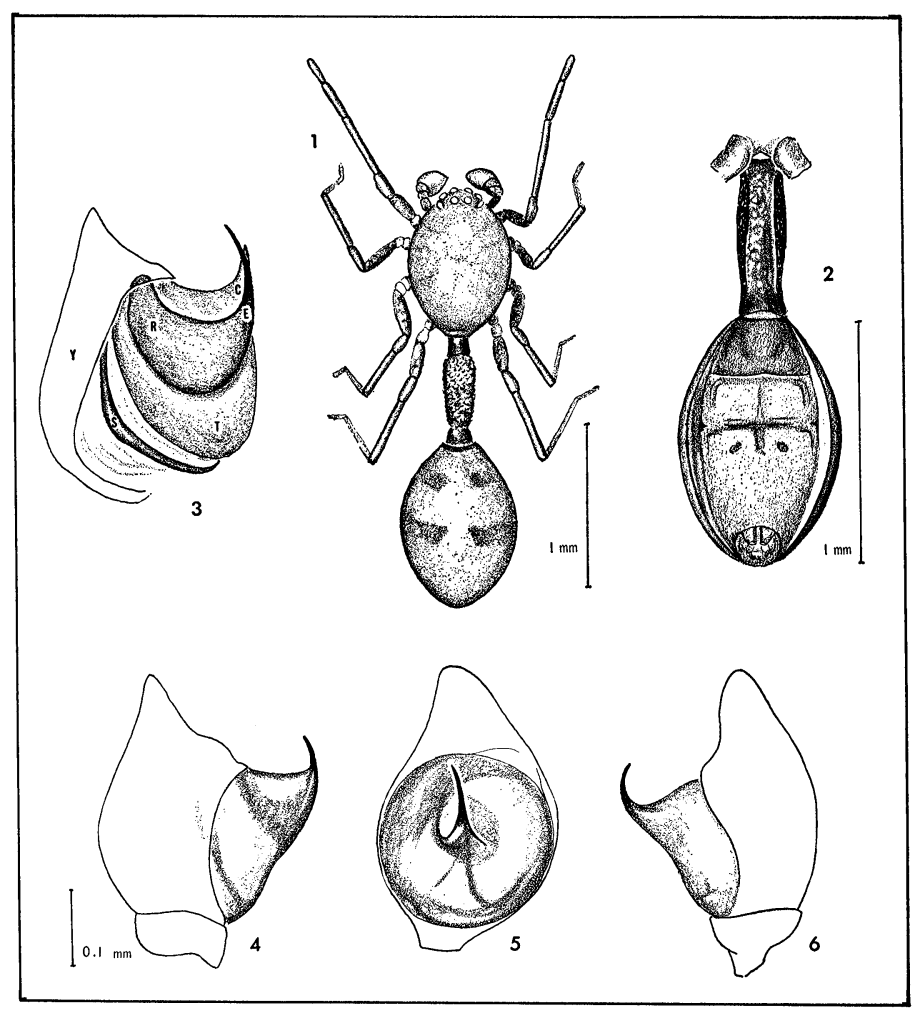

Figs. 1-6. Anatea formicaria Berland. Fig. 1. Dorsal view of male. Fig. 2. Ventral view of pedicel and abdomen. Figs. 3-6. Left palpus. 3. Expanded, mesoventral view. 4. Mesal view. 5. Ventral view. 6. Ectal view. Abbreviations. $\mathrm{C}$, conductor; $\mathrm{E}$, embolus; $\mathrm{S}$, subtegulum; T, tegulum; $\mathrm{Y}$, cymbium. 
is broadly joined to the embolus and the radix is absent. (It has since been found that the "radix" of theridiid spiders is homologous to the median apophysis of araneid spiders and the "median apophysis" to the radix).

Record: Male from rainforest at Ciu, near Mt. Canala, $300 \mathrm{~m}$, New Caledonia, 3r Dec. 1954 - I Jan. I955 (E. O. Wilson) in the Museum of Comparative Zoology.

\section{REFERENCES}

BERLAND, L.

1927. Sur une Araignée myrmécomorphe de Nouvelle-Calédonie. Bull. Soc. Entomol. France $95:$ 52-55.

Косн, C. L.

1851. Uebersicht des Arachiden - Systems. Heft $5: 41$.

Levi, H. W. and L. R. LeVI

1962. The Genera of the Spider Family Theridiidae. Bull. Mus. Comp. Zool. 127 (1):1-71.

Walckenaer, C. A.

1841. Histoire Naturelle des Insectes, Aptères. 2: 461-463. Paris. 

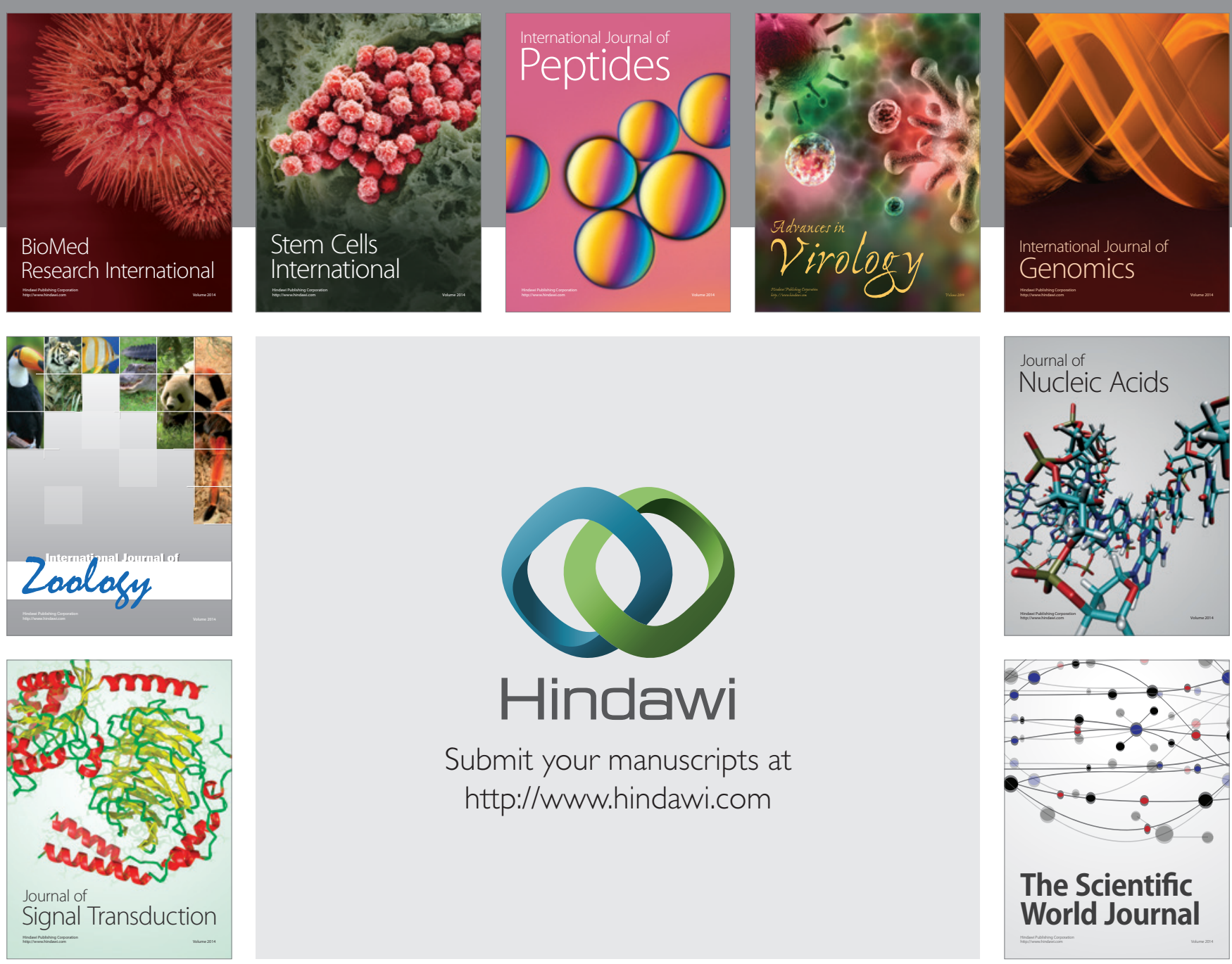

Submit your manuscripts at

http://www.hindawi.com
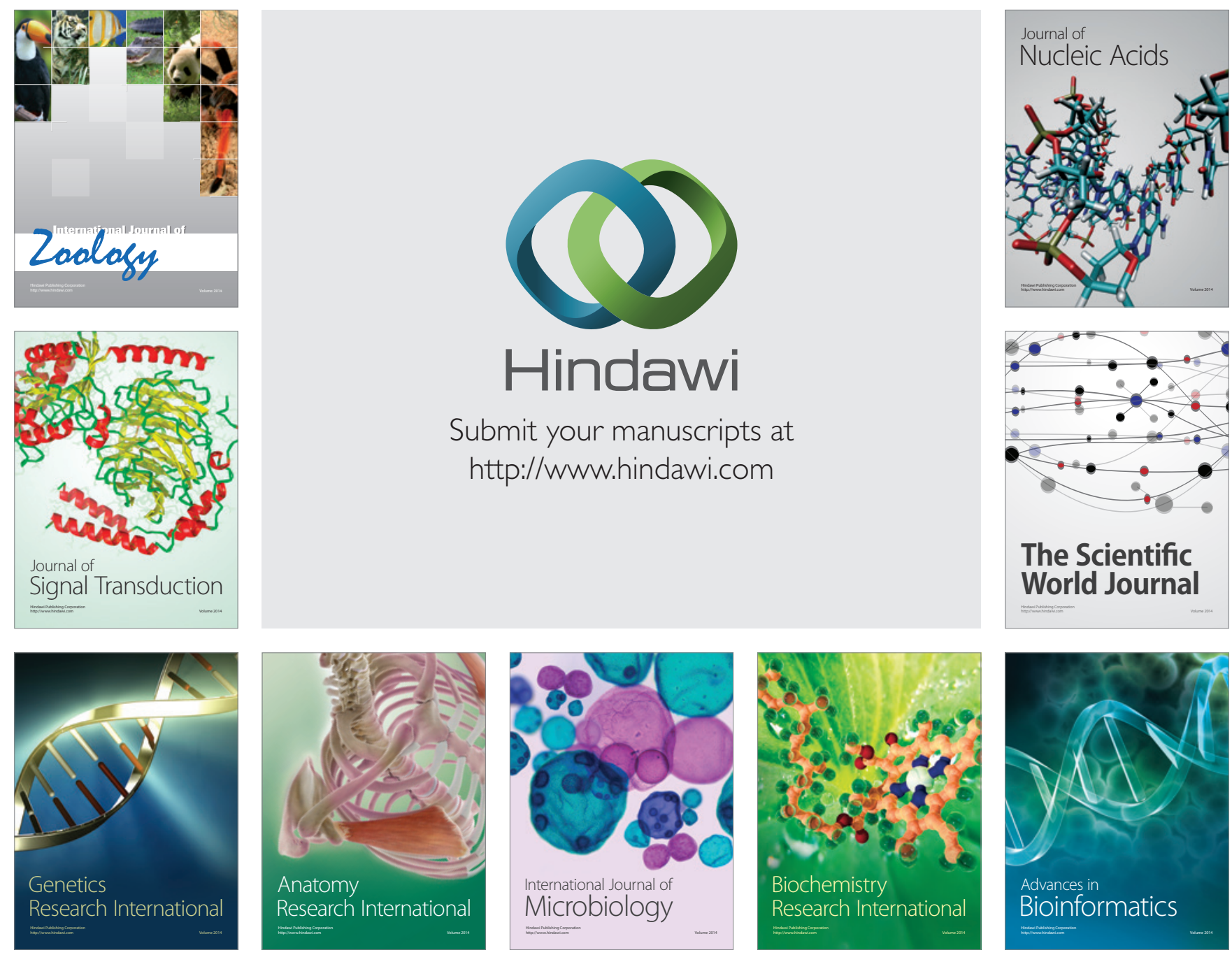

The Scientific World Journal
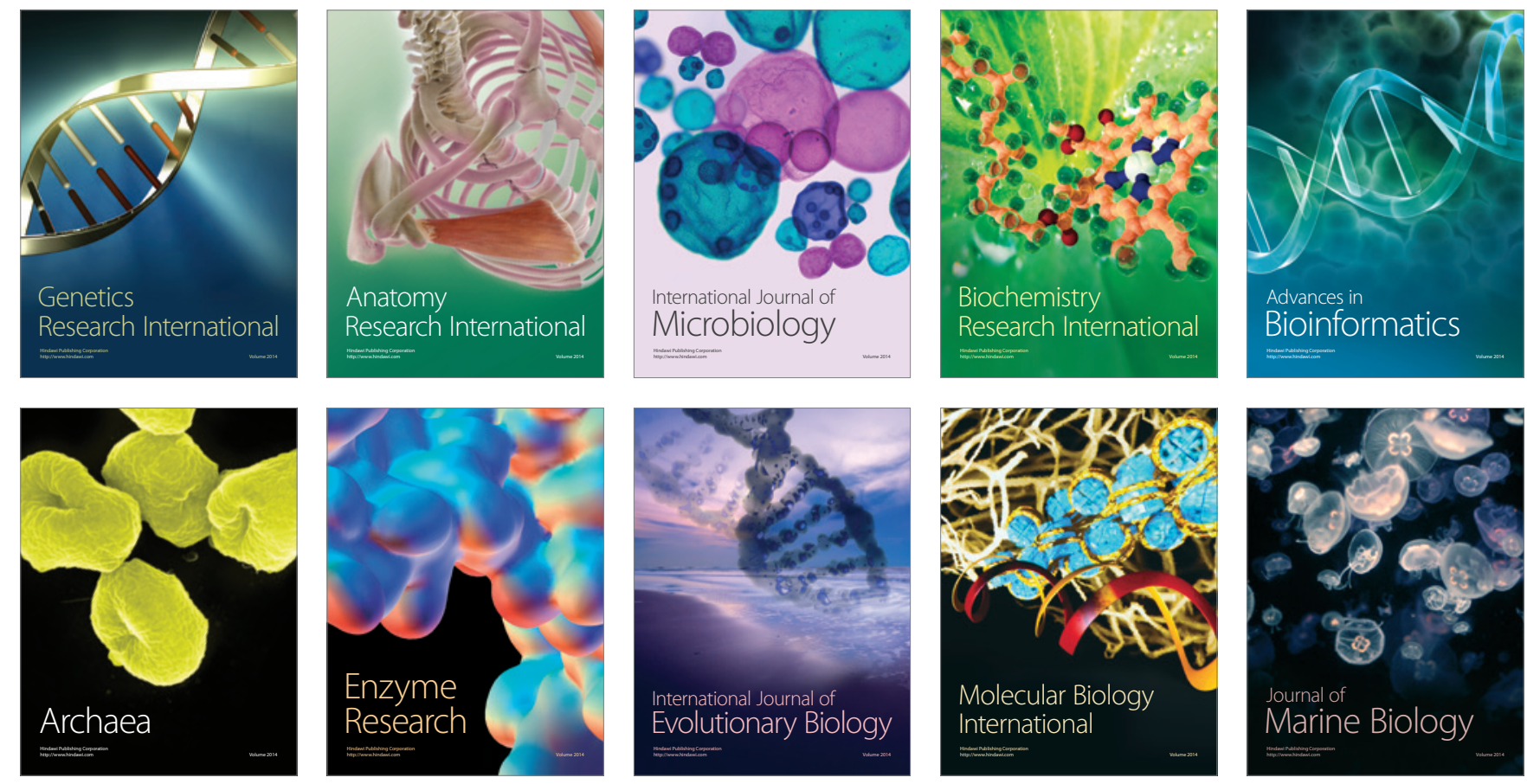